\title{
Polymorphic Behavior of Palm Oil and Modified Palm Oils
}

\author{
Hidetoshi Ishikawa, Makoto ShIOTA, Mototake Murakami and Ichiro NaKAJIMA \\ Technology and Research Institute, Snow Brand Milk Products Co., Ltd., 1-1-2, Minamidai, Kawagoe, Saitama 350-11, Japan
}

Received September 10, 1996

\begin{abstract}
Refined, bleached and deodorized palm oil, its purified palm triacylglycerol (PTG), palm olein (PO), palm stearin (PS) and high melting palm stearin (HMPS) fractions as well as randomized palm oil (RP) and its high melting randomized palm stearin (HMRPS) fractions were solidified at $5^{\circ} \mathrm{C}$ and kept isothermally at 10,20 and $30^{\circ} \mathrm{C}$ for 60 days. X-ray diffraction showed that PTG was in $\beta^{\prime}$ form crystals, while palm oil and RP were in both $\alpha$ and $\beta^{\prime}$ forms at $5 \mathrm{C}$. In HMPS and HMRPS, the higher percentage of $\beta$-transformation was observed with a higher content of trisaturated triacylglycerols and at a higher temperature. RP transformed from $\beta^{\prime}$ to the intermediate form crystals during prolonged storage. Other fats were stable in $\beta^{\prime}$ form crystals. Palm oil, RP, HMPS and HMRPS exhibited long-spacing values between those of tripalmitin and tristearin in $\alpha, \beta^{\prime}$ and $\beta$ modifications, respectively. This confirms that palm oil and its modified oils form a double-chain-length conformation.
\end{abstract}

Keywords: fractionation, interesterification, olein, palm oil, polymorphic transformation, stearin

Palm oil is a vegetable oil that has been widely used in the manufacture of products such as margarines, shortenings, cooking oils and confectionery fats (Kheiri, 1985; Murase, 1986; D’Souza et al., 1991; Ohfuji \& Fujiwara, 1994). The use of palm oil in foods, however, has been limited by its physical properties, namely, the presence of granular crystals (Ishikawa et al., 1980; Watanabe et al., 1992) and its low rate of crystallization (van Putte \& Bakker, 1987; Ng, 1990). In margarines and shortenings, solid fats should consist of $\beta^{\prime}$ form crystals, which confer a smooth texture to the products. On the other hand, the $\beta$ form crystals confer a rough texture to the products. The crystal forms depend on the triacylglycerol composition of blended oils and the rate of crystallization. Interesterification has been adopted to change the triacylglycerol composition. Random interesterification involves rearrangement of fatty acids within and between triacylglycerols. Rearrangement of acyl residues in triacylglycerols results in oils with new physical properties and different polymorphic behavior. Today, interesterification is used as frequently as fractionation in various areas. The interesterification of triacylglycerols has been extensively reviewed (Husted, 1976; Matsui, 1979; Laning, 1985; Mori, 1989).

D'Souza et al. (1992) studied the polymorphic behavior of solid fats found in commercially available soft margarines and suggested that solid fats can be provided by interesterified palm oil products. Duns (1985) studied the properties of palm oil before and after interesterification and concluded that the application of interesterification techniques, although useful, was restricted. However, little is known about fundamental research on the polymorphic behavior of modified palm oils.

In this study, we have dealt with modified palm oils formed by random interesterification and solvent-fractionation and investigated the effect of the triacylglycerol composition of these oils on their polymorphic behavior when placed at a constant temperature for a given period.

\section{Materials and Methods}

Refined, bleached and deodorized palm oil, and its palm olein (PO) and palm stearin (PS) fractions were obtained from The Nisshin Oil Mills, Ltd. (Tokyo). The purified palm triacylglycerol (PTG) fraction was separated from palm oil by thin-layer chromatography. The high melting palm stearin (HMPS) fraction was obtained by solvent-recrystallization as follows: PS was dissolved in acetone at the ratio of $1: 5(\mathrm{w}$ : v). The solution was left overnight in a water bath at $20^{\circ} \mathrm{C}$ to allow crystallization. The liquid fraction was then removed by filtration. The solvent was removed from the crystals under vacuum.

Random interesterification of palm oil was carried out at $80^{\circ} \mathrm{C}$ in an $1 l$ vessel. Sodium methoxide was used at a level of $0.3 \%$ by weight of the oil. High melting randomized palm stearin (HMRPS10, HMRPS20) fractions were obtained from randomized palm oil (RP) by solvent-crystallization (at 10 and $20^{\circ} \mathrm{C}$, respectively, in acetone). For comparison of polymorphic behavior, tripalmitin and tristearin (Sigma Chemical Co., St. Louis, MO) were used as standard trisaturated triacylglycerols.

The fatty acid compositions were determined by transesterification and analysis of methyl esters in a HewlettPackard gas chromatograph (Model 5890, Wilmington, DE) equipped with a flame ionization detector. Separations of the methyl esters were performed on a SP-2380 fused-silica capillary column $(30 \mathrm{~m} \times 0.32 \mathrm{~mm}$ i.d.; Supelco, Inc., Bellefonte, PA). The temperatures were $250^{\circ} \mathrm{C}$ for injection, $260^{\circ} \mathrm{C}$ for the detector, and $170^{\circ} \mathrm{C}$ for the column.

The diacylglycerol content in palm oil and PTG was measured with a TLC/FID Iatroscan TH-1000 (Iatron Labo., Inc., Tokyo).

The iodine value was determined according to the Wijs method, AOCS official method Cd 1-25.

The solid fat content (SFC) was measured by pulsed nuclear magnetic resonance ( $\mathrm{pNMR}$ ) in an NMR analyzer 
(Model SFC-900, Praxis Corp., San Antonio, TX) according to AOCS official method Cd 16-81.

Triacylglycerol compositions were determined by HPLC. The apparatus for HPLC was a Waters LC Module 1 equipped with a Waters differential refractometer (Model 410). Separation was performed on a Nova-Pak C18 column (300 mm $\times 3.9 \mathrm{~mm}$ i.d.; Waters, Millipore Corp., Milford, MA). The mobile phase was a mixture of acetone/acetonitrile (50:50), and the flow rate was $1 \mathrm{ml} / \mathrm{min}$ at $45^{\circ} \mathrm{C}$. Peak identification was based on the relative retention times reported in the literature (Defense, 1984, 1985).

X-ray diffractometry (CuK $\alpha$; RAD-IIIA, Rigaku Co., Ltd., Tokyo) was employed to measure the short and long spacings. The fat samples were first heated at $80^{\circ} \mathrm{C}$ for $1 \mathrm{~h}$, then cooled to $5^{\circ} \mathrm{C}$ for $1 \mathrm{~h}$, and finally stored at 10,20 and $30^{\circ} \mathrm{C}$ until analyzed. Quantitative evaluation of the $\beta$ form was based on the relative densities of the short spacings at $4.2 \AA$ and $4.6 \AA$, which are characteristic of the $\beta^{\prime}$ and $\beta$ forms, respectively (Yap et al., 1989). The percentage of the $\beta$ form was calculated from:

$$
\begin{aligned}
\beta \%= & (\text { peak height at } 4.6 \AA) /(\text { peak heights at } 4.2 \text { and } 4.6 \AA) \\
& \times 100
\end{aligned}
$$

\section{Results and Discussion}

Chemical and physical characteristics The fatty acid composition and iodine value of palm oil and modified palm oils are shown in Table 1. Palmitic acid (16:0) tended to predominate in the stearin fraction while the fatty acid composition of PTG and PO was similar to that of the original palm oil. On the other hand, the iodine value of the high melting stearin fractions varied within a wide range. As shown in Table 2, the solid fat content of palm oil was markedly lower than that of PTG at 10 and $20^{\circ} \mathrm{C}$, probably because partial acylglycerols and free fatty acids form eutectic compounds with triacylglycerols (Jacobsberg \& Oh, 1976).

Palm oil and fractions The short and long spacings for various fats are shown in Table 3. Palm oil cooled rapidly to $5^{\circ} \mathrm{C}$ showed a mixture of $\alpha$ and $\beta^{\prime}$ form crystals, then maintained the $\beta^{\prime}$ form crystals at 10 and $20^{\circ} \mathrm{C}$. PTG was in $\beta^{\prime}$ form crystals at 5,10 and $20^{\circ} \mathrm{C}$. The crystal form observed at $5^{\circ} \mathrm{C}$ depended on the diacylglycerol content of palm oil and PTG (1.7\% and 0.0\%, respectively). Persmark et al. showed that the lifetime of $\alpha$ form crystals is considerably increased by the presence of partial acylglycerols (Berger, 1975; Persmark et al., 1976).

X-ray diffraction lines over $d=8 \AA(\mathrm{CuK} \alpha: 2 \theta<10)$ are called long spacings. Chapman (1962) reported that the lines are closely related to the length of the fatty acid in triacylglycerol, mainly the carbon number. On the other hand, each of the chain-packing subcells is characterized by X-ray diffraction lines in a wide-angle region, that is, between $3.6 \AA$ and $5.0 \AA$ ( $\mathrm{CuK} \alpha: 2 \theta=25-18$, short spacings). In long spacings, palm oil solidified from the melt exhibited a strong line at $47.2 \AA$ and a weak line at $43.3 \AA$. It is assumed that the crystallized palm oil consists mainly of $\alpha$ form crystals in which the unit cells are perpendicular to the methyl endgroup plane and the hydrocarbon chains are hexagonally closed packed (Persmark et al., 1976). When the crystallized palm oil was stored at higher temperatures of 10 and $20^{\circ} \mathrm{C}$, the $\alpha$ form crystals quickly transformed into $\beta^{\prime}$ form crystals with short spacings at $4.37,4.23,3.90 \AA$ within 1 day. Palm oil contains a high proportion of POP (symmetric 1,3-di-palmitoyl-2-oleoyl glycerol). Sato et al. (1989) reported that the $\alpha$, pseudo- $\beta_{2}{ }^{\prime}$ and pseudo- $\beta_{1}{ }^{\prime}$ form crystals of POP had a double-chain-length structure; whereas, the $\gamma, \delta, \beta_{2}$ and $\beta_{1}$ crystals had a triple-chain-length structure. The long spacing value of $43.3 \AA$ in the $\beta^{\prime}$ form corresponded to the doublechain-length structure, and palm oil containing many triacylglycerols exhibited one modification. HMPS (IV 14) showed $\alpha$ form crystals at $5^{\circ} \mathrm{C}$ and transformed to $\beta$ form crystals at 10,20 and $30^{\circ} \mathrm{C}$. From the triacylglycerol composition (Table 4), HMPS which consisted mainly of trisaturated triacylglycerols, PPP (60\%) and PPS (11\%) crystallized initially in $\alpha$ form crystals which transformed into $\beta$ form crystals when the storage temperature was increased, like a monoacid triacyl-

\begin{tabular}{|c|c|c|c|c|c|c|c|c|}
\hline Fatty acid & Palm & $\mathrm{PTG}^{a)}$ & $\mathrm{PO}^{b)}$ & $\mathrm{PS}^{c)}$ & $\mathrm{HMPS}^{d)}$ & $\mathrm{RP}^{e)}$ & HMRPS $10^{f)}$ & HMRPS20 \\
\hline $12: 0$ & 0.2 & 0.2 & 1.4 & 0.1 & & 0.2 & 0.1 & 0.1 \\
\hline $14: 0$ & 1.2 & 1.1 & 1.6 & 1.5 & 1.9 & 1.1 & 1.0 & 1.0 \\
\hline $16: 0$ & 45.9 & 45.4 & 40.1 & 47.6 & 73.1 & 43.6 & 60.0 & 72.5 \\
\hline $16: 1$ & 0.4 & 0.3 & 0.3 & 0.3 & & & 0.2 & 0.2 \\
\hline $18: 0$ & 4.4 & 4.6 & 5.0 & 10.5 & 8.4 & 4.8 & 6.1 & 6.7 \\
\hline $18: 1$ & 37.8 & 38.3 & 41.7 & 32.6 & 13.3 & 39.5 & 24.8 & 15.4 \\
\hline $18: 2$ & 9.4 & 9.5 & 9.6 & 7.3 & 2.8 & 9.8 & 6.0 & 3.4 \\
\hline $20: 0$ & 0.7 & 0.6 & 0.3 & 0.4 & 0.5 & 0.7 & 1.2 & 0.5 \\
\hline lodine value & 53.0 & 53.1 & 56.0 & 45.1 & 14.4 & 53.4 & 35.3 & 22.5 \\
\hline
\end{tabular}

Table 1. Fatty acid composition (\%) and iodine value of palm oil and its fractions.

a) Purified palm triacylglycerol fraction, ${ }^{b)}$ palm olein, ${ }^{c}$ palm stearin, ${ }^{d)}$ high melting palm stearin $\left(20^{\circ} \mathrm{C}\right.$, acetone), $\left.{ }^{e}\right)$ randomized palm oil, ${ }^{f)}$ high melting randomized palm stearin $\left(10^{\circ} \mathrm{C}\right.$, acetone $\left.),{ }^{g}\right)$ high melting randomized palm stearin $\left(20^{\circ} \mathrm{C}\right.$, acetone).

\begin{tabular}{|c|c|c|c|c|c|c|c|c|}
\hline & Palm & $\mathrm{PTG}^{a)}$ & $\mathrm{PO}^{b)}$ & PS $^{(1)}$ & HMPS $^{d)}$ & $\mathrm{RP}^{e)}$ & HMRPS $10^{n}$ & HMRPS20 \\
\hline $10^{\circ} \mathrm{C}$ & 51.7 & 66.6 & 34.5 & 60.4 & 100 & 47.9 & 100 & 100 \\
\hline $20^{\circ} \mathrm{C}$ & 20.1 & 24.4 & 6.0 & 34.3 & 100 & 30.0 & 74.4 & 100 \\
\hline $30^{\circ} \mathrm{C}$ & 11.0 & 11.9 & 1.5 & 25.3 & 100 & 18.8 & 66.2 & 100 \\
\hline
\end{tabular}

Table 2. Solid fat content (\%) of palm oil and its fractions.

${ }^{a)}$ Purified palm triacylglycerol fraction, ${ }^{b)}$ palm olein, ${ }^{c)}$ palm stearin, ${ }^{d)}$ high melting palm stearin $\left(20^{\circ} \mathrm{C}\right.$, acetone), ${ }^{e)}$ randomized palm oil, ${ }^{f}$ high melting randomized palm stearin $\left(10^{\circ} \mathrm{C}\right.$, acetone $),{ }^{g}$ high melting randomized palm stearin $\left(20^{\circ} \mathrm{C}\right.$, acetone). 
Table 3. Short and long spacings $(\AA)$ of palm oil and its fractions at different temperatures.

\begin{tabular}{|c|c|c|c|c|c|c|c|c|c|c|c|}
\hline \multirow{2}{*}{$\begin{array}{l}\text { Condition } \\
5^{\circ} \mathrm{C}, 1 \mathrm{~h}\end{array}$} & \multicolumn{2}{|l|}{ Fat } & \multicolumn{3}{|c|}{ Short spacings } & \multicolumn{5}{|c|}{ Long spacings ${ }^{a, b)}$} & \multirow{2}{*}{$\begin{array}{l}\text { Form } \\
\alpha>\beta^{\prime}\end{array}$} \\
\hline & Palm & & $4.35(\mathrm{~s})$ & $4.23(w)$ & $3.90(w)$ & & $47.2(\mathrm{~s})$ & $43.3(w)$ & $15.9(w)$ & $14.4(w)$ & \\
\hline & $\mathrm{PTG}^{c)}$ & & $4.35(\mathrm{~s})$ & $4.23(\mathrm{~s})$ & $3.90(\mathrm{~m})$ & & & $43.3(\mathrm{~s})$ & & & $\beta^{\prime}$ \\
\hline & $\mathrm{PO}^{d)}$ & & $4.35(\mathrm{~s})$ & $4.23(\mathrm{~m})$ & $3.90(\mathrm{~m})$ & & & $43.5(w)$ & & & $\alpha \ll \beta^{\prime}$ \\
\hline & $\mathrm{HMPS}^{e)}$ & & \multicolumn{4}{|c|}{$4.15(\mathrm{~s})$} & $46.0(\mathrm{~s})$ & & $15.5(\mathrm{~s})$ & 14.1(w) & $\alpha$ \\
\hline & $\mathrm{RP} f$ & & $4.35(\mathrm{~s})$ & $4.23(\mathrm{~s})$ & $3.90(\mathrm{~m})$ & & $47.2(\mathrm{~m})$ & $43.3(\mathrm{~m})$ & $15.9(w)$ & $14.5(\mathrm{~m})$ & $\alpha+\beta^{\prime}$ \\
\hline & HMRPS109) & $4.62(w)$ & $4.39(\mathrm{~s})$ & $4.27(\mathrm{~s})$ & $3.90(\mathrm{~s})$ & & & $43.9(\mathrm{~s})$ & & & $\beta^{\prime} \gg \beta$ \\
\hline & HMRPS20 $0^{h)}$ & $4.62(\mathrm{~s})$ & $4.35(\mathrm{~s})$ & $4.27(\mathrm{~s})$ & $3.90(s)$ & & & $43.7(\mathrm{~s})$ & & & $\beta^{\prime}>\beta$ \\
\hline \multirow[t]{7}{*}{$10^{\circ} \mathrm{C}, 60$ days } & Palm & & $4.37(\mathrm{~s})$ & $4.23(\mathrm{~s})$ & $3.90(\mathrm{~s})$ & & & $43.3(\mathrm{~s})$ & & $14.4(\mathrm{~m})$ & $\beta^{\prime}$ \\
\hline & PTG & & $4.37(\mathrm{~s})$ & $4.23(\mathrm{~s})$ & $3.90(\mathrm{~s})$ & & & $43.3(\mathrm{~s})$ & & $14.4(\mathrm{~m})$ & $\beta^{\prime}$ \\
\hline & $\mathrm{PO}$ & & $4.37(\mathrm{~s})$ & $4.23(\mathrm{~s})$ & $3.90(\mathrm{~s})$ & & & $43.3(\mathrm{~m})$ & & $14.4(\mathrm{~m})$ & $\beta^{\prime}$ \\
\hline & HMPS & $4.60(\mathrm{~s})$ & & & $3.90(\mathrm{~s})$ & $3.77(\mathrm{~m})$ & & $42.0(\mathrm{~s})$ & & $14.1(\mathrm{~m})$ & $\beta$ \\
\hline & $\mathrm{RP}$ & $4.62(\mathrm{~s})$ & $4.37(\mathrm{~s})$ & $4.23(\mathrm{~s})$ & $3.90(\mathrm{~s})$ & & & $43.3(\mathrm{~s})$ & & $14.5(\mathrm{~m})$ & $\beta^{\prime}>\beta$ \\
\hline & HMRPS10 & $4.62(\mathrm{~s})$ & $4.37(s)$ & $4.27(\mathrm{~s})$ & $3.88(\mathrm{~s})$ & & & $43.3(\mathrm{~s})$ & & $14.3(\mathrm{~m})$ & $\beta^{\prime}<\beta$ \\
\hline & HMRPS20 & $4.62(\mathrm{~s})$ & $4.37(\mathrm{~m})$ & $4.23(\mathrm{~m})$ & $3.88(\mathrm{~s})$ & & & $42.4(s)$ & & $14.2(\mathrm{~m})$ & $\beta^{\prime}<\beta$ \\
\hline \multirow{6}{*}{$20^{\circ} \mathrm{C}, 60$ days } & PTG & & $4.37(\mathrm{~s})$ & $4.23(\mathrm{~s})$ & $3.90(\mathrm{~s})$ & & & $42.9(\mathrm{~s})$ & & $14.3(\mathrm{~m})$ & $\beta^{\prime}$ \\
\hline & $\mathrm{PO}$ & & $4.37(\mathrm{~s})$ & $4.23(\mathrm{~s})$ & $3.90(\mathrm{~s})$ & & & $42.9(\mathrm{~s})$ & & $14.4(\mathrm{~m})$ & $\beta^{\prime}$ \\
\hline & HMPS & $4.60(\mathrm{~s})$ & & & $3.90(\mathrm{~s})$ & $3.75(\mathrm{~s})$ & & $41.3(\mathrm{~s})$ & & $13.8(\mathrm{~m})$ & $\beta$ \\
\hline & $\mathrm{RP}$ & $4.62(\mathrm{~s})$ & $4.37(\mathrm{~m})$ & $4.23(\mathrm{~m})$ & $3.88(\mathrm{~m})$ & $3.78(w)$ & & $42.9(\mathrm{~s})$ & & $14.4(\mathrm{~m})$ & $\beta^{\prime} \ll \beta$ \\
\hline & HMRPS10 & $4.62(\mathrm{~s})$ & $4.39(\mathrm{~s})$ & $4.25(\mathrm{~s})$ & $3.88(\mathrm{~s})$ & & & $42.9(\mathrm{~s})$ & & $14.3(\mathrm{~m})$ & $\beta^{\prime}<\beta$ \\
\hline & HMRPS20 & $4.62(\mathrm{~s})$ & & & $3.90(\mathrm{~s})$ & $3.80(\mathrm{~m})$ & & $42.2(\mathrm{~s})$ & & $14.2(\mathrm{~m})$ & $\beta$ \\
\hline \multirow[t]{4}{*}{$30^{\circ} \mathrm{C}, 60$ days } & HMPS & $4.60(\mathrm{~s})$ & & & $3.90(\mathrm{~s})$ & $3.74(\mathrm{~s})$ & & $41.3(\mathrm{~s})$ & & $13.8(\mathrm{~m})$ & $\beta$ \\
\hline & HMRPS10 & $4.62(\mathrm{~m})$ & & & $3.92(\mathrm{~m})$ & $3.80(\mathrm{~m})$ & & $42.2(\mathrm{~s})$ & & $14.1(\mathrm{~m})$ & $\beta$ \\
\hline & HMRPS20 & $4.62(\mathrm{~s})$ & & & $3.90(\mathrm{~s})$ & $3.77(\mathrm{~m})$ & & $42.0(\mathrm{~s})$ & & $14.0(\mathrm{~m})$ & $\beta$ \\
\hline & Tripalmitin & $4.60(\mathrm{~s})$ & & & $3.86(\mathrm{~s})$ & $3.70(\mathrm{~s})$ & & $40.6(s)$ & & $13.7(\mathrm{~m})$ & $\beta$ \\
\hline
\end{tabular}

a) Band intensities are indicated as s, strong; $\mathrm{m}$, medium; $\mathrm{w}$, weak.

b) Predominate short spacings of $\beta^{\prime}, 4.37,4.23$ and $3.90 \AA ; \beta, 4.60,3.86$ and $3.70 \AA$.

${ }^{c}$ Purified palm triacylglycerol fraction, ${ }^{())}$palm olein, ${ }^{e)}$ high melting palm stearin $\left(20^{\circ} \mathrm{C}\right.$, acetone $),{ }^{f}$ randomized palm oil, $\left.{ }^{g}\right)$ high melting randomized palm stearin $\left(10^{\circ} \mathrm{C}\right.$, acetone $),{ }^{h)}$ high melting randomized palm stearin $\left(20^{\circ} \mathrm{C}\right.$, acetone).

Table 4. Triacylglycerol composition (\%) of palm oil and its fractions as determined by HPLC.

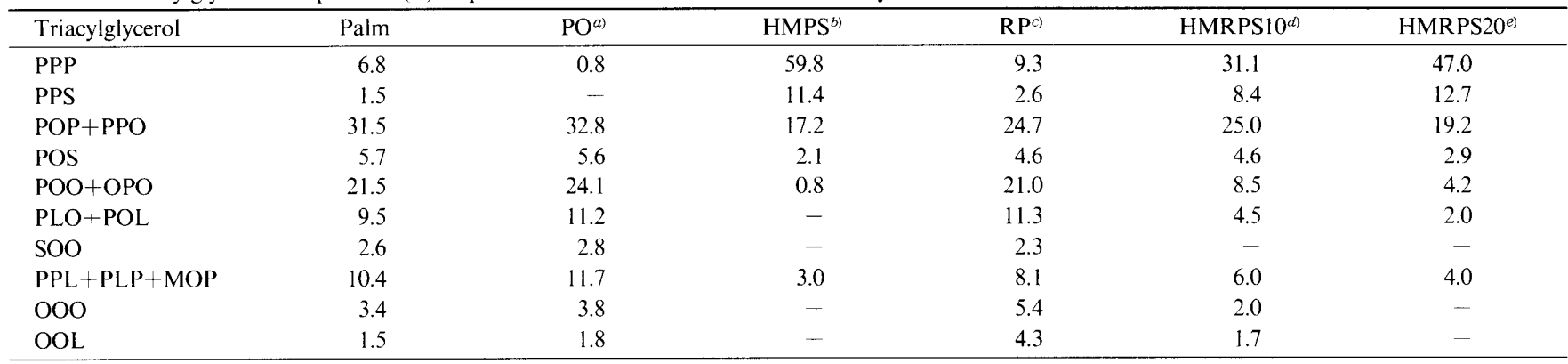

a) Palm olein, ${ }^{b)}$ high melting palm stearin $\left(20^{\circ} \mathrm{C}\right.$, acetone $),{ }^{c}$ randomized palm oil, ${ }^{d)}$ high melting randomized palm stearin $\left(10^{\circ} \mathrm{C}\right.$, acetone), ${ }^{e)}$ high melting randomized palm stearin $\left(20^{\circ} \mathrm{C}\right.$, acetone).

glycerol.

Randomized palm oil and fractions RP showed a mixture of $\alpha$ and $\beta^{\prime}$ form crystals at $5^{\circ} \mathrm{C}$, like palm oil. On the other hand, it exhibited a weak line at $4.6 \AA$ after 1 day at 10 or $20^{\circ} \mathrm{C}$. During the period at 10 or $20^{\circ} \mathrm{C}$, there was a transformation to $\beta$ form crystals. The crystals, however, did not show a perfect $\beta$ form but an intermediate form. As for the long spacings of RP, the length of the $c$-axis in the unit cell was the same as that of palm oil in $\beta^{\prime}$ form crystals. In case of HMRPS (IV 35, 23), the X-ray diffraction data indicated that they had transformed from $\beta^{\prime}$ to $\beta$ form crystals. Especially, the higher melting fraction HMRPS20 changed to $\beta$ form crystals in a short time.

Chain-packing in each modification The long and short spacings in each modification are summarized in Table 5. Tripalmitin showed the shortest long spacing for each polymorph among the samples analyzed, and tristearin showed the longest ones. Palm oil, RP and other fractions exhibited intermediate values between tripalmitin and tristearin. This confirms that palm oil and RP form doublechain-length conformation, because they had the same long spacings in the $\alpha$ and $\beta^{\prime}$ modifications.

Relation between triacylglycerol composition and $\beta$ transformation We investigated the relation between the percentage of $\beta$ form crystals and the content of trisaturated triacylglycerols in higher melting stearins and tripalmitin stored at various temperatures for different periods of time (Figs. 1, 2). High melting stearin fractions easily transformed from $\beta^{\prime}$ to $\beta$ form crystals as the trisaturated triacylglycerol content and storage temperature increased. However, the development of $\beta$ form crystals in HMPS was low when stored at $10^{\circ} \mathrm{C}$ for 1 day. On the other hand, tripalmitin was 
Table 5. Characteristic long and short spacings ( $\mathrm{A}$ ) of various fat samples.

\begin{tabular}{|c|c|c|c|c|c|c|}
\hline \multirow{2}{*}{$\frac{\text { Polymorph }}{\alpha}$} & \multirow{2}{*}{$\frac{\text { Fat }}{\text { Tripalmitin }}$} & \multicolumn{3}{|c|}{ Short spacings } & \multicolumn{2}{|c|}{ Long spacings } \\
\hline & & \multicolumn{3}{|c|}{4.15} & 46.0 & 15.3 \\
\hline & HMPS $^{a)}$ & \multicolumn{3}{|c|}{4.15} & 46.0 & 15.5 \\
\hline & Palm & \multicolumn{3}{|c|}{4.20} & 47.2 & 15.9 \\
\hline & $\mathrm{RP}^{b l}$ & \multicolumn{3}{|c|}{4.20} & 47.2 & 15.9 \\
\hline & Tristearin & \multicolumn{3}{|c|}{4.15} & 50.6 & \\
\hline \multirow[t]{4}{*}{$\beta^{\prime}$} & Tripalmitin & & 4.20 & 3.80 & 42.6 & \\
\hline & Palm & 4.37 & 4.23 & 3.90 & 43.3 & 14.4 \\
\hline & RP & 4.37 & 4.23 & 3.90 & 43.3 & 14.4 \\
\hline & Tristearin & & 4.20 & 3.80 & 47.2 & \\
\hline \multirow[t]{5}{*}{$\beta$} & Tripalmitin & 4.60 & 3.86 & 3.70 & 40.6 & 13.7 \\
\hline & HMPS & 4.60 & 3.90 & 3.74 & 41.3 & 13.8 \\
\hline & HMRPS20 & 4.62 & 3.90 & 3.77 & 42.0 & 14.0 \\
\hline & HMRPS10 & 4.62 & 3.92 & 3.80 & 42.2 & 14.1 \\
\hline & Tristearin & 4.60 & 3.86 & 3.70 & 44.6 & \\
\hline
\end{tabular}

a) High melting palm stearin $\left(20^{\circ} \mathrm{C}\right.$, acetone $),{ }^{b)}$ randomized palm oil, ${ }^{c}$ high melting randomized palm stearin $\left(20^{\circ} \mathrm{C}\right.$, acetone $),{ }^{d)}$ high melting randomized palm stearin $\left(10^{\circ} \mathrm{C}\right.$, acetone $)$.

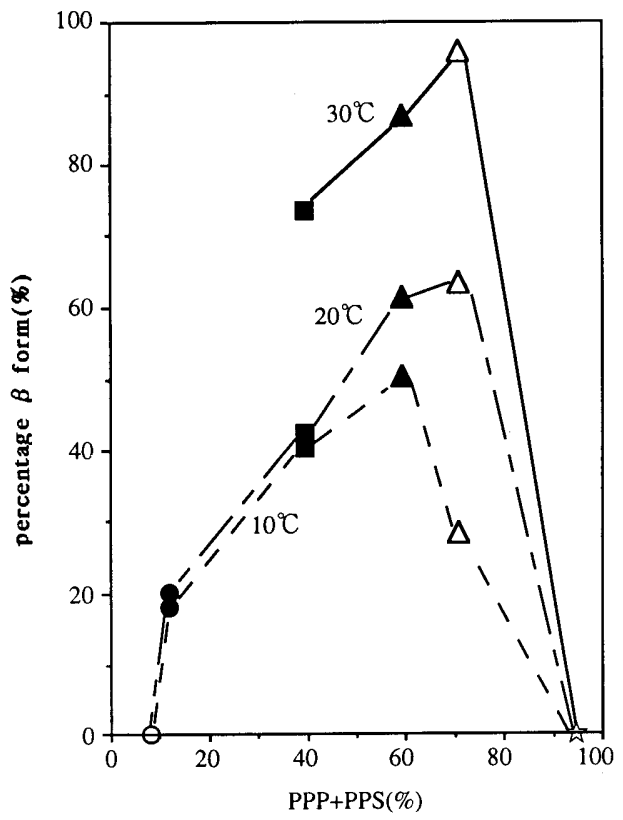

Fig. 1. Relation between the percentage of $\beta$ form crystals and the trisaturated triacylglycerol content ( I day after solidification). palm oil, $\triangle$ high melting palm stearin, $\bullet$ randomized palm oil, $\boldsymbol{\square}$ high melting randomized palm stearin $\left(10^{\circ} \mathrm{C}\right.$, acetone $), \Delta$ high melting randomized palm stearin $\left(20^{\circ} \mathrm{C}\right.$, acetone $)$, tripalmitin

in $\alpha$ form crystals when stored at 10 or $20^{\circ} \mathrm{C}$ but transformed to $\beta$ form crystals when stored at $30^{\circ} \mathrm{C}$ for 60 days.

Data on triacylgycerol composition, polymorphic transformation, and the length of long spacings in $\beta$ form crystals can be summarized as follows. High melting stearin fractions transformed into $\beta$ form crystals in proportion to the trisaturated triacylglycerol content. The length of long spacings in $\beta$ form crystals approached that of tripalmitin as the trisaturated triacylglycerol content increased. Lower fractionation temperature yielded more middle melting triacylglycerols in fractionated solid fats: POP, PPO, POS. Hence the long spacings of original fats were longer than those of high melting stearin fractions. On the other hand, RP transformed from $\beta^{\prime}$ to $\beta$ form crystals faster than HMRPS 10 when stored at $20^{\circ} \mathrm{C}$ for 60 days in spite of its lower trisaturated triacyl-

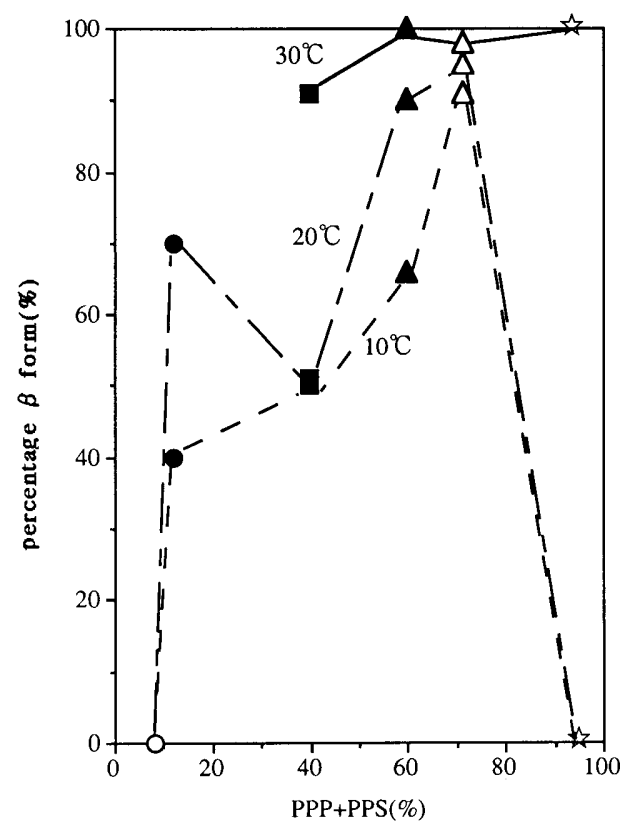

Fig. 2. Relation between the percentage of $\beta$ form crystals and the trisaturated triacylglycerol content ( 60 days after solidification). palm oil, $\triangle$ high melting palm stearin, randomized palm oil, $\boldsymbol{a}$ high melting randomized palm stearin $\left(10^{\circ} \mathrm{C}\right.$, acetone), $\Delta$ high melting randomized palm stearin $\left(20^{\circ} \mathrm{C}\right.$, acetone), tripalmitin.

glycerol content. We assumed that diunsaturated and triunsaturated acylglycerols in RP accelerated the transformation at $20^{\circ} \mathrm{C}$ by behaving as a solvent, thus causing the migration of molecular chains in the lattice.

When the content of monoacid trisaturated triacylglycerols such as tripalmitin was extremely high, the percentage of transformation from $\alpha$ to $\beta$ form crystals under $30^{\circ} \mathrm{C}$ was lower than that of other stearin fractions.

The results obtained from this study indicated that the $\beta$-transformation of modified palm oils can be affected by the trisaturated triacylglycerol content and storage temperature. However, the physical characteristics and polymorphic behavior of these oils when incorporated into a margarine formula would be considerably influenced by other factors such as the triacylgycerol composition of blended oils, the presence and kind of emulsifiers, and the processing conditions.

\section{References}

Berger, K.G. (1975). Uses of palm oil in the food industry. Chem. Ind., 1, $910-913$.

Chapman, D. (1962). The polymorphism of glycerides. Chem. Rev., 62, 433-456.

Defense, E. (1984). Application de la chromatographie liquide haute performance a l'analyse des triglycerides des graisses vegetales et animales et de leurs fractions obtenues par cristallisation fractionnee. Rev. Franc. Corps Gras, 31, 123-129.

Defense, E. (1985). Fractionation of palm oil. J. Am. Oil Chem. Soc., 62, 376-385.

D'Souza, V., deMan, J.M. and deMan, L. (1991). Chemical and physical properties of the high melting glyceride fractions of commercial margarines. J. Am. Oil Chem. Soc., 68, 153-162.

D'Souza, V., deMan, J.M. and deMan, L. (1992). Chemical and physical properties of the solid fats in commercial soft margarines. J. Am. Oil Chem. Soc., 69, 1198-1205.

Duns, L.M. (1985). Palm oil in margarines and shortenings. J. Am. Oil 
Chem. Soc., 62, 408-410.

Husted, H.H. (1976). Interesterification of edible oils. J. Am. Oil Chem. Soc., 53, 390-392.

Ishikawa, H., Mizuguchi, T. and Kondo, S. (1980). Studies on granular crystals growing in palm oil. J. Jpn. Oil Chem. Soc., 29, 235-242. Jacobsberg, B. and Oh Chuan Ho (1976). Studies in palm oil crystallization. J. Am. Oil Chem. Soc., 53, 609-617.

Kheiri, A.S.M. (1985). Palm oil products in cooking fats. J. Am. Oil Chem. Soc., 62, 410-416.

Laning, S.J. (1985). Chemical interesterification of palm, palm kernel and coconut oils. J. Jpn. Oil Chem. Soc., 62, 400-405.

Matsui, N. (1979). Interesterification and its application to food fat industries. J. Jpn. Oil Chem. Soc., 28, 680-688.

Mori, H. (1989). Solidification problems in preparation of fats. In "Crystallization and Polymorphism of Fats and Fatty Acids," ed. by N. Garti and K. Sato. Marcel Dekker, Inc., New York, pp. 423442.

Murase, Y. (1986). Current situation of palm oil production and utilization. J. Jpn. Soc. Food Sci. Technol., 33, 291-299.
$\mathrm{Ng}$, W.L. (1990). A study of the kinetics of nucleation in a palm oil melt. J. Am. Oil Chem. Soc., 67, 879-882.

Ohfuji, T. and Fujiwara, K. (1994). Production and use of palm oil. In "Nutritional and Health Aspects of Palm Oil," ed. by K. Aibara. International Life Sciences Institute of Japan, Tokyo, pp. 32-60.

Persmark, U., Melin, K.A. and Stahl, P.O. (1976). Palm oil, its polymorphism and solidification properties. Rev. Ital. Sostanze Grasse, 53, 301-308.

Sato, K., Arishima, T., Way, Z.H., Ojima, K., Sagi, N. and Mori, H. (1989). Polymorphism of POP and SOS. J. Am. Oil Chem. Soc., 66, 664-679.

van Putte, K.P.A.M. and Bakker, B.H. (1987). Crystallization kinetics of palm oil. J. Am. Oil Chem. Soc., 64, 1138-1143.

Watanabe, A., Tashima, I., Matsuzaki, N., Kurashige, J. and Sato, K. (1992). On the formation of granular crystals in fat blends containing palm oil. J. Am. Oil Chem. Soc., 69, 1077-1080.

Yap, P.H., deMan, J.M. and deMan, L. (1989). Polymorphism of palm oil and palm oil products. J. Am. Oil Chem. Soc., 66, 693-697. 